\title{
Austenite Decomposition and Precipitation Behavior of Plastically Deformed Low-Si Microalloyed Steel
}

\author{
Adam Grajcar ${ }^{1, *(1)}$, Mateusz Morawiec ${ }^{1}$ and Wladyslaw Zalecki ${ }^{2}$ (i) \\ 1 Institute of Engineering Materials and Biomaterials, Silesian University of Technology, 18A Konarskiego \\ Street, 44-100 Gliwice, Poland; mateusz.morawiec@polsl.pl \\ 2 Department of Process Simulation, Institute for Ferrous Metallurgy, 12-14 K. Miarki Street, 44-100 Gliwice, \\ Poland; wzalecki@imz.pl \\ * Correspondence: adam.grajcar@polsl.pl; Tel.: +48-32-237-2933
}

Received: 21 November 2018; Accepted: 3 December 2018; Published: 6 December 2018

\begin{abstract}
The aim of the present study is to assess the effects of hot deformation and cooling paths on the phase transformation kinetics in a precipitation-strengthened automotive $0.2 \mathrm{C}-1.5 \mathrm{Mn}-0.5 \mathrm{Si}$ steel with $\mathrm{Nb}$ and Ti microadditions. The analysis of the precipitation processes was performed while taking into account equilibrium calculations and phase transitions resulting from calculated time-temperature-transformation (TTT) and continuous cooling transformation (CCT) diagrams. The austenite decomposition was monitored based on thermodynamic calculations of the volume fraction evolution of individual phases as a function of temperature. The calculations were compared to real CCT and DCCT (deformation continuous cooling transformation) diagrams produced using dilatometric tests. The research included the identification of the microstructure of the nondeformed and thermomechanically processed supercooled austenite products formed at various cooling rates. The complex interactions between the precipitation process, hot deformation, and cooling schedules are linked.
\end{abstract}

Keywords: austenite decomposition; high-strength steel; microstructure evolution; phase transformation

\section{Introduction}

The strengthening of advanced ferrous alloys can be achieved in many ways, including solid solution strengthening, grain refinement, cold deformation, precipitation phenomena, phase transformations, high-pressure methods, etc. [1-3]. One of the most interesting and evolving groups of advanced steels for the automotive industry is the multiphase transformation-induced plasticity (TRIP)-aided steels consisting of ferrite, bainite, and retained austenite [4-6]. These steels utilize different strengthening mechanisms to improve their strength level, but the most important is the strain-induced transformation of retained austenite into martensite [7-9]. This transformation takes place during the cold forming of steel sheets and results in improving both strength and plasticity. This phenomenon is called the transformation-induced plasticity (TRIP) effect [10-13].

A special feature of TRIP steels is the presence of carbide-free bainite, which can be formed during a multistep heat treatment using increased Si and/or Al additions [14]. These elements are necessary to prevent carbide precipitation under conditions of isothermal bainitic transformation. Hence, carbon enriches an austenitic phase instead of forming carbide precipitation and subsequently allows the stabilization of a retained austenite amount at room temperature in equilibrium with carbide-free bainite. A typical addition of silicon to the steel is approximately $1.5 \%$. Unfortunately, such a high amount of this element deteriorates the sheet wettability by liquid zinc during hot-dip galvanizing [15]. Therefore, industrial requirements prefer low-Si grades in TRIP-aided steels [16,17]. The decrease of the solid solution potential of silicon and a resulting decrease of the strength level (Al has a smaller solid 
solution strengthening effect) can be compensated by Nb, Ti, and/or V microalloyed additions [18-22]. These elements form stable nitrides and carbonitrides during hot working in the austenite region. The increase of strength is due to grain refinement and precipitation strengthening by dispersive particles of MX-type phases [23-27]. These microalloyed multiphase steels are of special interest to the automotive industry because of the weight reduction potential $[11,12,15]$. Since the most investigated TRIP-aided steels are manufactured by cold deformation and subsequent intercritical annealing $[15,23,25]$, this work is focused on hot-deformed TRIP-aided steels with low Si content.

The stabilization of retained austenite is affected by three major factors: an enrichment of the $\gamma$ phase in $\mathrm{C}$ and $\mathrm{Mn}$, its grain size, and its dislocation density [9,28]. In low-Si grades, the driving force for carbon enrichment of the austenite is smaller. Thus, the two other factors, i.e., the grain size reduction and increased dislocation density, become of great importance for the potential stabilization of retained austenite. It is assumed that both factors can be obtained for hot-rolled microalloying-aided sheet products. Therefore, the aim of this work is to monitor precipitation processes in the austenite and to assess undeformed and deformed austenite decomposition under conditions of continuous cooling of a low-Si microalloyed steel.

\section{Materials and Methods}

The chemical composition of the investigated steel is presented in Table 1 . The silicon addition was minimized to $0.5 \%$, and this low level was compensated for by microadditions of $\mathrm{Nb}$ and $\mathrm{Ti}$. The liquid metal was vacuum-melted in an induction furnace VSG-50 (Balzers, Asslar, Germany) and subsequently cast as a $25 \mathrm{~kg}$ ingot, which was forged between $1200{ }^{\circ} \mathrm{C}$ and $900{ }^{\circ} \mathrm{C}$ to a thickness of $22 \mathrm{~mm}$.

Table 1. Chemical composition of the investigated steel.

\begin{tabular}{ccccccccc}
\hline $\mathbf{C}$ & $\mathbf{M n}$ & $\mathbf{S i}$ & $\mathbf{A l}$ & $\mathbf{S}$ & $\mathbf{P}$ & $\mathbf{N b}$ & $\mathbf{T i}$ & $\mathbf{N}$ \\
\hline $0.2 \pm 0.01$ & $1.41 \pm 0.03$ & $0.50 \pm 0.03$ & $0.020 \pm 0.002$ & $0.008 \pm 0.001$ & $0.014 \pm 0.002$ & $0.027 \pm 0.001$ & $0.010 \pm 0.001$ & $0.0047 \pm 0.0002$ \\
\hline
\end{tabular}

The precipitation behavior of MX-type phases with $\mathrm{Nb}$ and Ti microadditions formed under thermodynamic equilibrium conditions was analyzed as the first step. The temperature of TiN precipitation was determined using Equation (1). In the same way, the solubility product of niobium carbonitride was calculated based on Equation (2). This equation takes into account the real concentrations of $\mathrm{Mn}$ and $\mathrm{Si}$ in the steel. Thermodynamic calculations of the phase transformations of undercooled austenite were simulated using the JMatPro software (version 8.0, Sente Software Ltd, Guildford, UK) package. The CCT (continuous cooling transformation) diagram and TTT (time-temperature-transformation) diagram were designated for continuous cooling and for isothermal cooling, respectively.

The analysis of the real phase transformation kinetics was performed using dilatometric tests. For these tests, $\Phi 4 \mathrm{~mm} \times \Phi 3 \mathrm{~mm} \times 7 \mathrm{~mm}$ tubular samples and $\Phi 4 \mathrm{~mm} \times 7 \mathrm{~mm}$ cylindrical specimens were prepared. The dilatometric experiments were conducted with the use of a DIL805 dilatometer produced by Bähr Thermoanalyse GmbH (Hüllhorst, Germany), equipped with an LVDT-type measuring head with a theoretical resolution of $\pm 0.057 \mu \mathrm{m}$. The study involved classical heat treatment tests and thermomechanical tests, i.e., for plastically deformed samples after austenitization. For nondeformed tests, the tubular samples after the austenitization step at $1100{ }^{\circ} \mathrm{C}$ were cooled at a rate of $5{ }^{\circ} \mathrm{C} / \mathrm{s}$ to the temperature of $875{ }^{\circ} \mathrm{C}$, isothermally held for $20 \mathrm{~s}$, and finally cooled to room temperature at cooling rates ranging from 260 to $0.17^{\circ} \mathrm{C} / \mathrm{s}$. The plastically deformed samples were subjected to a similar heat treatment procedure, but after cooling the samples to $875^{\circ} \mathrm{C}$ and before final cooling they were plastically compressed with a reduction of $50 \%$ at a strain rate of $1 \mathrm{~s}^{-1}$. Microscopic tests after dilatometric analyses included classical metallographic procedures using a light microscopy (Leica MEF 4A, Wetzlar, Germany) technique with 3\% nital etching. 


\section{Results and Discussion}

\subsection{Thermodynamic Calculations of Precipitation Processes}

A first step of the study included a thermodynamic analysis of precipitation processes occurring in the austenite containing microalloyed additions. To determine the equilibrium precipitation temperatures of MX-type phases with $\mathrm{Nb}$ and $\mathrm{Ti}$, Equations (1) and (2) were used. The calculations were based on the following constant values: $A=8000, B=0.32$ for TiN and $A=6440, B=2.26$ for $\mathrm{Nb}(\mathrm{CN})[24]$.

$$
\begin{gathered}
\log [\mathrm{Ti}][\mathrm{N}]=0.32-8000 / \mathrm{T} \\
\log [\mathrm{Nb}]\left[\mathrm{C}+\frac{12}{14} N\right]=2.26+\frac{838[\mathrm{Mn}]^{0.246}-1730[\mathrm{Si}]^{0.594}-6440}{T}
\end{gathered}
$$

Tables 2 and 3 present the solubility products for the analyzed MX-type phases as a function of temperature. The parameter $\mathrm{k}_{\mathrm{s}}$ determines the total concentrations of microalloying elements and metalloids possibly dissolved at temperature $\mathrm{T}$ under thermodynamic equilibrium conditions. It is clearly seen that the values of solubility products for compounds $\mathrm{TiN}$ and $\mathrm{Nb}(\mathrm{CN})$ increase with increasing temperature. Comparing the solubility products of the $\mathrm{TiN}$ and $\mathrm{Nb}(\mathrm{CN})$ phases, it can be seen that higher stability is retained by TiN because it has much lower values of parameter $\mathrm{k}_{\mathrm{s}}$.

Table 2. Solubility products for TiN at various temperatures in the austenite.

\begin{tabular}{ccc}
\hline Temperature $[K]$ & Log $\mathbf{k}_{\mathbf{s}}$ & $\mathbf{k}_{\mathbf{s}}$ \\
\hline 1423 & -5.30193 & 0.00000499 \\
1373 & -5.50666 & 0.00000311 \\
1323 & -5.72686 & 0.00000188 \\
1273 & -5.96437 & 0.00000109 \\
1223 & -6.22129 & 0.00000060 \\
1173 & -6.50012 & 0.00000032 \\
1123 & -6.80378 & 0.00000016 \\
\hline
\end{tabular}

Table 3. Solubility products for $\mathrm{Nb}(\mathrm{CN})$ at various temperatures in the austenite calculated by taking into account $\mathrm{Mn}$ and Si contents in the analyzed steel.

\begin{tabular}{ccc}
\hline Temperature [K] & Log $\mathbf{k}_{\mathbf{s}}$ & $\mathbf{k}_{\mathbf{s}}$ \\
\hline 1423 & -2.43025 & 0.003713 \\
1373 & -2.60105 & 0.002506 \\
1323 & -2.78476 & 0.001641 \\
1273 & -2.98291 & 0.00104 \\
1223 & -3.19725 & 0.000635 \\
1173 & -3.42987 & 0.000372 \\
1123 & -3.68321 & 0.000207 \\
\hline
\end{tabular}

On the basis of the data in Tables 2 and 3, the corresponding mutual solubility limit diagrams for individual MX-type interstitial phases were prepared (Figures 1 and 2). On their basis, the chemical composition of the solid solution can be calculated, i.e., concentrations of microadditions and metalloids in solid solution and concentrations of microadditions and metalloids fixed in the stable MX phase, as well as a mass fraction of the particles precipitated from the matrix [24]. Figure 1 presents the solubility diagram for titanium and nitrogen in the austenite for two selected temperatures. The first temperature of $1100{ }^{\circ} \mathrm{C}$ corresponds to the austenitizing temperature, whereas the second one $\left(875{ }^{\circ} \mathrm{C}\right)$ is the deformation temperature before cooling. Thus, the initial and final chemical compositions of the solid solution can be determined under equilibrium conditions. The chemical composition of the analyzed steel is also marked on the diagram. The line that represents a stoichiometric ratio of titanium to nitrogen of 48:14 is marked on the diagram. By moving the stoichiometric line parallel 
to the point indicating the chemical composition of the analyzed steel, an intersection point with the curve indicating the solubility product at a given temperature can be obtained.

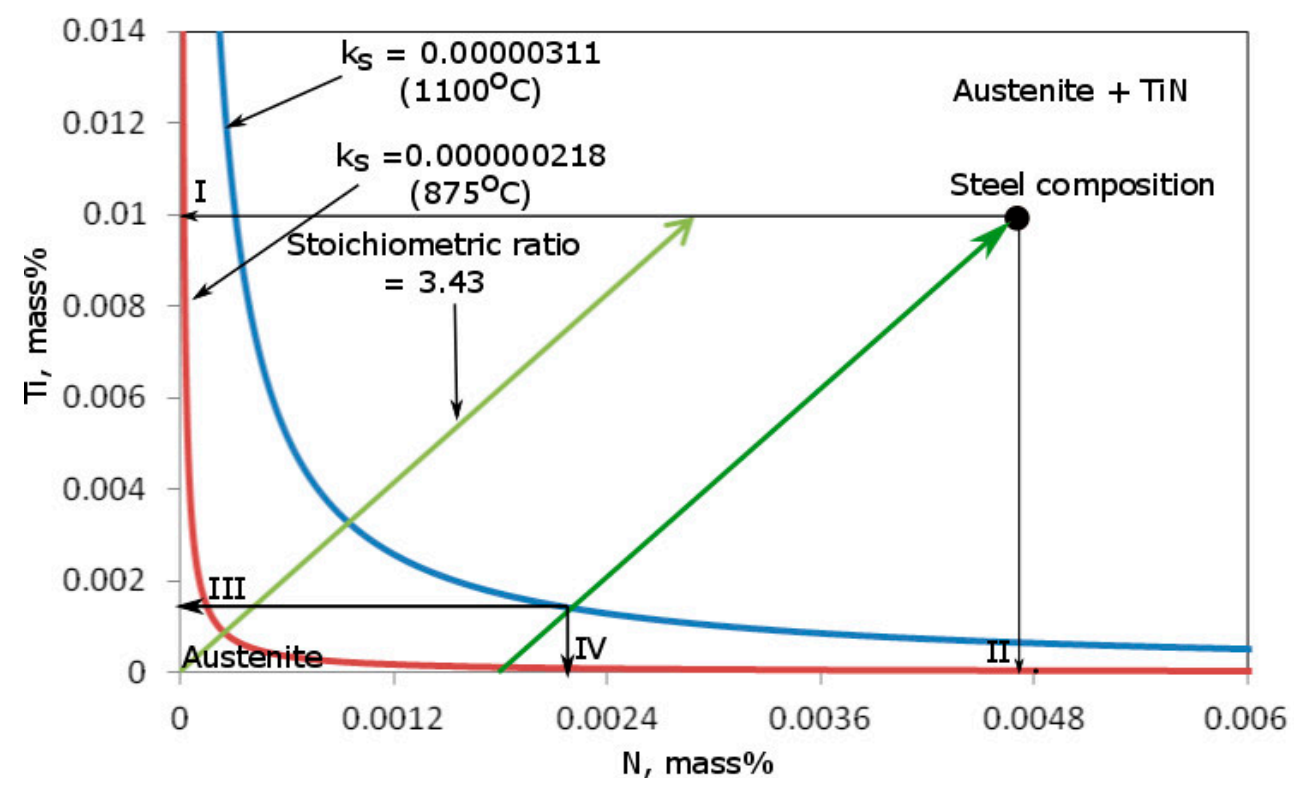

Figure 1. Limits of mutual solubility of titanium and nitrogen at $1100{ }^{\circ} \mathrm{C}$ and $875^{\circ} \mathrm{C}$ in the austenite with the stoichiometric ratio between $\mathrm{Ti}$ and $\mathrm{N}$.

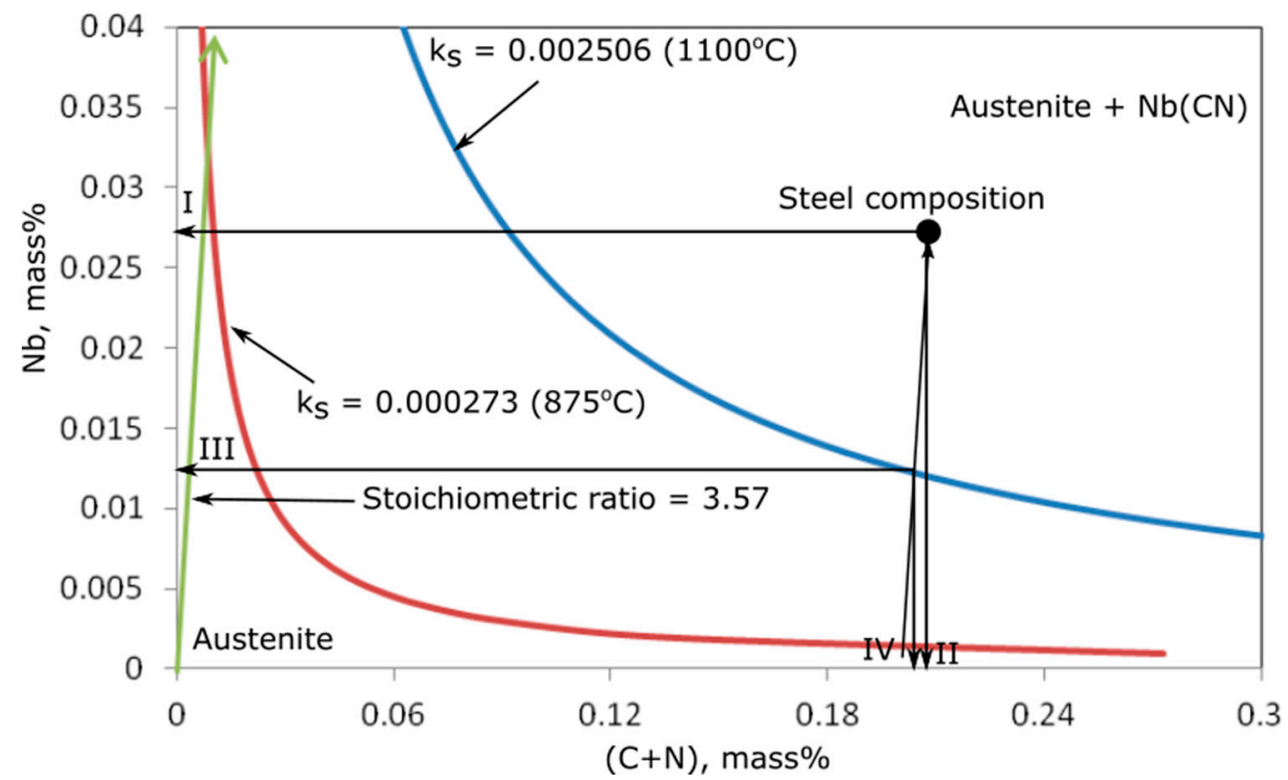

Figure 2. Limits of mutual solubility of niobium as well as carbon and nitrogen at $1100{ }^{\circ} \mathrm{C}$ and $875^{\circ} \mathrm{C}$ in the austenite range with the stoichiometric ratio between $\mathrm{Nb}$ and $(\mathrm{C}, \mathrm{N})$.

It can be seen that at the temperature of $1100{ }^{\circ} \mathrm{C}$ the amount of dissolved $\mathrm{Ti}$ in the austenite is equal to 0.0014 mass $\%$ (point III on the diagram), and that circa 0.0021 mass $\%$ of nitrogen was dissolved in the austenite (point IV). This means that only a small fraction of titanium and nitrogen is dissolved in the solid solution whereas the rest is fixed into TiN, limiting grain growth during the austenitization step. When the temperature of the steel decreases to $875^{\circ} \mathrm{C}$, the amount of Ti dissolved in the solid solution is close to 0 . All Ti is bound in TiN. At the same time, the difference in Ti and N contents between the analyzed steel composition and the corresponding intersection lines signify the mass fractions of titanium $\mathrm{Ti}_{\mathrm{TiN}}$ and nitrogen $\mathrm{N}_{\mathrm{TiN}}$ bound in TiN, respectively. 
A similar analysis for niobium, carbon, and nitrogen was performed, and the results are presented in Figure 2. At $1100{ }^{\circ} \mathrm{C}$, the amount of niobium dissolved in the solid solution is 0.012 mass $\%$ together with 0.21 mass $\%$ of combined $(\mathrm{C}+\mathrm{N})$. This means that ca. $50 \%$ of the total niobium is dissolved. When the temperature of the steel decreases to $875{ }^{\circ} \mathrm{C}$, there is only a small concentration of $\mathrm{Nb}$ dissolved in the austenite. Practically all niobium is bound in $\mathrm{Nb}(\mathrm{CN})$. These results illustrate that between the austenitization step and the plastic deformation temperature, the $\mathrm{Nb}(\mathrm{C}, \mathrm{N})$ precipitation process should occur. This may lead to grain refinement because the nitrides and carbonitrides slow down grain growth considerably $[23,29]$.

Tables 4 and 5 present the calculated chemical compositions of the austenite as well as TiN and $\mathrm{Nb}(\mathrm{C}, \mathrm{N})$ mass\% fractions, which stay in equilibrium at particular temperatures. Figures 3 and 4 show the corresponding results of the performed calculations of the solubility of $\operatorname{TiN}$ and $\mathrm{Nb}(\mathrm{C}, \mathrm{N})$. In the case of TiN we can see a gradual decrease in the contents of nitrogen and titanium dissolved in solid solution and a subsequent increase in the TiN fraction occuring with decreasing temperature (Figure 3 ). At the temperature of $1100{ }^{\circ} \mathrm{C}$, there is ca. $14 \%$ of the titanium dissolved in solid solution together with $46 \%$ of the nitrogen. When the temperature decreases to $850{ }^{\circ} \mathrm{C}$, the titanium is entirely bound in TiN. The amount of dissolved nitrogen at $850{ }^{\circ} \mathrm{C}$ is 0.0018 mass $\%$, which corresponds to the results in Figure 1. The amount of Ti required to bind all nitrogen into TiN is 3.4 times the mass percent value of $\mathrm{N}$ in the steel. In the case of the analyzed steel, the amount of Ti needed for the complete binding of $\mathrm{N}$ is 0.016 mass $\%$. Taking into account the limited titanium concentration in the steel $(0.01 \%)$, this means that some of the nitrogen content remains dissolved. In practice, this part should be fixed in $\mathrm{Nb}(\mathrm{C}, \mathrm{N})$. The available content of $\mathrm{N}$ at $850{ }^{\circ} \mathrm{C}$ is about 0.018 mass $\%$ (Figure $3 b$ ).

Table 4. Contents of [Ti] and [N] dissolved in the austenite and mass $\%$ (TiN) separated from the matrix at various temperatures.

\begin{tabular}{ccccccc}
\hline \multicolumn{2}{c}{ Temperature } & \multirow{2}{*}{ Log ks } & ks & [Ti], mass\% & [N], mass\% & (TiN), mass\% \\
\cline { 1 - 2 }$\left[{ }^{\circ} \mathbf{C}\right]$ & {$[\mathbf{K}]$} & & & & & \\
\hline 1150 & 1423 & -5.30193 & 0.00000499 & 0.00200 & 0.002386 & 0.010314 \\
1100 & 1373 & -5.50666 & 0.00000311 & 0.00140 & 0.002191 & 0.011109 \\
1050 & 1323 & -5.72686 & 0.00000188 & 0.00092 & 0.002043 & 0.011739 \\
1000 & 1273 & -5.96437 & 0.00000109 & 0.00056 & 0.001939 & 0.012201 \\
950 & 1223 & -6.22129 & 0.00000060 & 0.000321 & 0.001869 & 0.012510 \\
900 & 1173 & -6.50012 & 0.00000032 & 0.000173 & 0.001825 & 0.012702 \\
850 & 1123 & -6.80378 & 0.00000016 & 0.0000086 & 0.001800 & 0.012891 \\
\hline
\end{tabular}

Table 5. Contents of $[\mathrm{Nb}]$ and $[\mathrm{C}, \mathrm{N}]$ dissolved in the austenite and mass $\%(\mathrm{NbCN})$ separated from the matrix at various temperatures.

\begin{tabular}{|c|c|c|c|c|c|c|}
\hline \multicolumn{2}{|c|}{ Temperature } & \multirow{2}{*}{$\log k s$} & \multirow{2}{*}{ ks } & \multirow{2}{*}[\mathrm{Nb}]{, mass $\%$} & \multirow{2}{*}[\mathrm{C},\mathrm{N}]{, mass $\%$} & \multirow{2}{*}{$(\mathrm{NbCN})$, mass $\%$} \\
\hline$\left[{ }^{\circ} \mathrm{C}\right]$ & [K] & & & & & \\
\hline 1150 & 1423 & -2.43025 & 0.003713 & 0.0390 & 0.211679 & 0 \\
\hline 1100 & 1373 & -2.60105 & 0.002506 & 0.0250 & 0.208265 & 0.003735 \\
\hline 1050 & 1323 & -2.78476 & 0.001641 & 0.0164 & 0.205846 & 0.015390 \\
\hline 1000 & 1273 & -2.98291 & 0.001040 & 0.0100 & 0.204198 & 0.022802 \\
\hline 950 & 1223 & -3.19725 & 0.000635 & 0.0059 & 0.203120 & 0.027980 \\
\hline 900 & 1173 & -3.42987 & 0.000372 & 0.0033 & 0.202447 & 0.031253 \\
\hline 850 & 1123 & -3.68321 & 0.000207 & 0.00175 & 0.202046 & 0.033204 \\
\hline
\end{tabular}



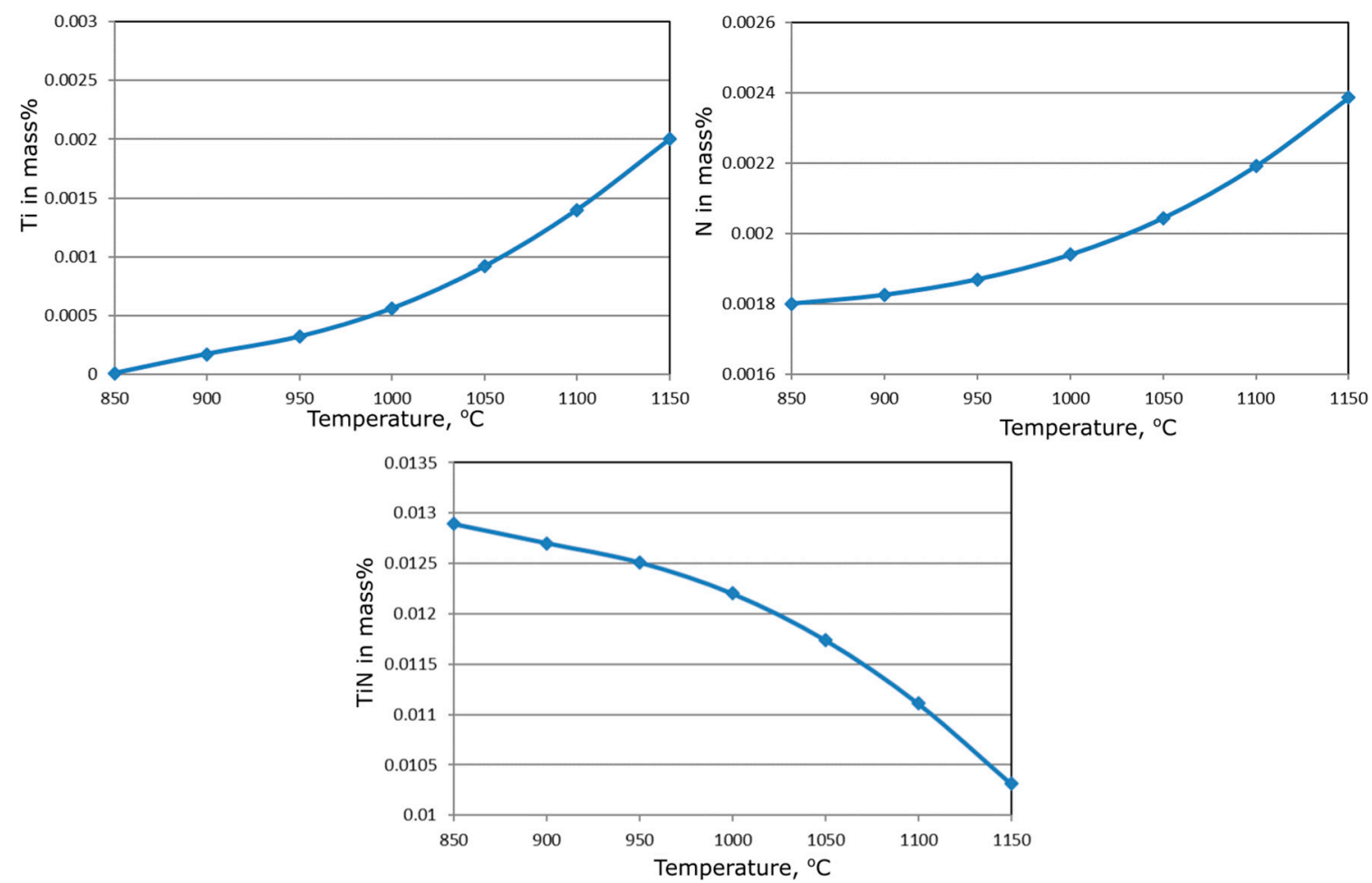

Figure 3. Temperature range of TiN precipitation in the austenite: (a) mass\% $\mathrm{Ti}$ dissolved in the solid solution; (b) mass\% $\mathrm{N}$ dissolved in the solid solution; (c) mass\% fraction of (TiN) compound precipitated in the austenite.
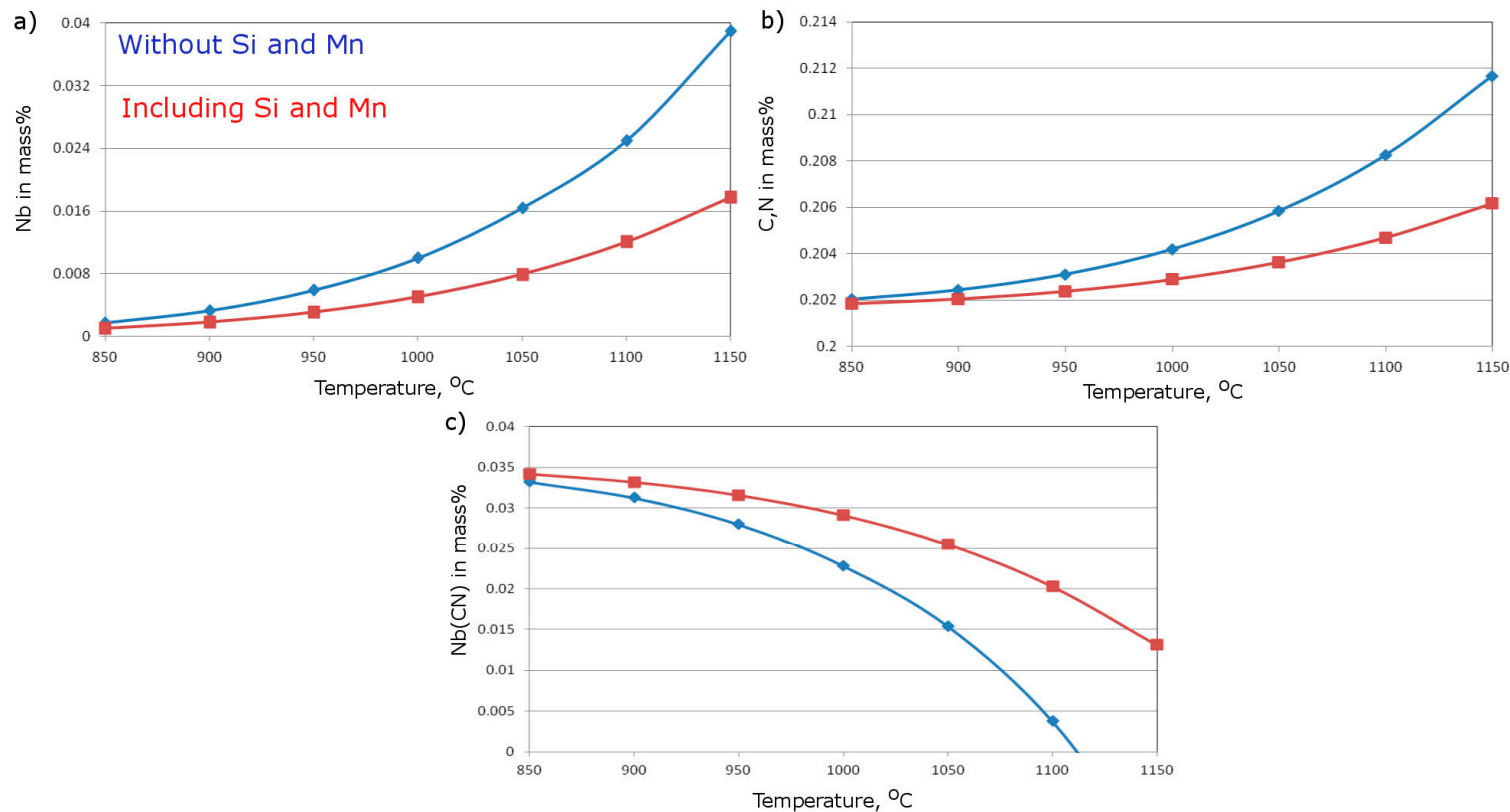

Figure 4. Temperature range of $\mathrm{Nb}(\mathrm{CN})$ precipitation in the austenite: (a) mass $\% \mathrm{Nb}$ dissolved in the solid solution; (b) combined mass\% $(\mathrm{C}, \mathrm{N})$ dissolved in the solid solution; (c) mass \% fraction of $\mathrm{Nb}(\mathrm{CN})$ compound precipitated in the austenite.

The second analysis concerned $\mathrm{Nb}(\mathrm{CN})$. The corresponding results are presented in Figure 4. First, the calculations for the precipitation of $\mathrm{Nb}(\mathrm{CN})$ without $\mathrm{Mn}$ and Si were carried out (blue lines in Figure 4). The precipitation of $\mathrm{Nb}(\mathrm{CN})$ starts at around $1110{ }^{\circ} \mathrm{C}$, and its amount increases with decreasing temperature. It is accompanied by a decrease in the amount of $\mathrm{Nb}$ dissolved in the solid solution. At the temperature of $850{ }^{\circ} \mathrm{C}$, almost all niobium is bound in $\mathrm{Nb}(\mathrm{CN})$. After that, the 
calculations included the $\mathrm{Si}$ and Mn concentrations in the steel. It can be seen that after taking into account the $\mathrm{Si}$ and $\mathrm{Mn}$ concentrations, the amount of precipitated $\mathrm{Nb}(\mathrm{CN})$ increases at a particular temperature. The difference in the amount of precipitated $\mathrm{Nb}(\mathrm{CN})$ is higher at high temperatures and decreases along with the temperature drop. Moreover, the precipitation process starts at a higher temperature. Siciliano and Jonas [29] observed that in the case of steel including microadditions of $\mathrm{Nb}$, an increase in the Si content leads to an acceleration of the precipitation of $\mathrm{Nb}(\mathrm{CN})$. On the other hand, manganese decreases $\mathrm{Nb}$ diffusivity in the austenite and inhibits the precipitation of $\mathrm{Nb}(\mathrm{CN})$ [30]. These results were obtained for the equilibrium conditions. Under real cooling conditions, some higher part of the microadditions stays supersaturated in the solid solution due to undercooling [27,31]. Comparing the relative effects of $\mathrm{Si}$ and $\mathrm{Mn}$ in the analyzed steel, one can note that the accelerating effect of the addition of $0.5 \% \mathrm{Si}$ is greater than the decelerating effect of $1.4 \% \mathrm{Mn}$ addition.

\subsection{Thermodynamic Calculations of Phase Transformations}

To analyze the phase transformations of the steel under equilibrium conditions, JMatPro software was used [32]. Figure 5 presents the evolution of the phases as a function of temperature. It represents a change in the microstructure state during a very slow cooling corresponding to thermodynamic equilibrium conditions. The graph enables us to identify temperatures of particular phase transitions and to assess a volume fraction of the particular phases at a given temperature. The liquidus temperature is equal to ca. $1510{ }^{\circ} \mathrm{C}$, and the solidus temperature is equal to $1460{ }^{\circ} \mathrm{C}$. The equilibrium temperature $\left(\mathrm{A}_{\mathrm{e} 1}\right)$ for the alpha phase is $688^{\circ} \mathrm{C}$, and the area of austenite phase is stable from $688^{\circ} \mathrm{C}$ to $1460{ }^{\circ} \mathrm{C}$. The calculated amount of austenite during the austenitzation at $1100{ }^{\circ} \mathrm{C}$ is almost $100 \%$. It can be seen that the remaining part is $\mathrm{M}(\mathrm{C}, \mathrm{N})$-type carbides, which is in accordance with the previously described precipitation behaviour. The analysis shows that at room temperature under equilibrium conditions, some fraction of cementite can exist in the microstructure.

Fe-0.02Al-1.41Mn-0.027Nb-0.5Si-0.01Ti-0.2C-0.0047N-0.014P-0.008S wt(\%)

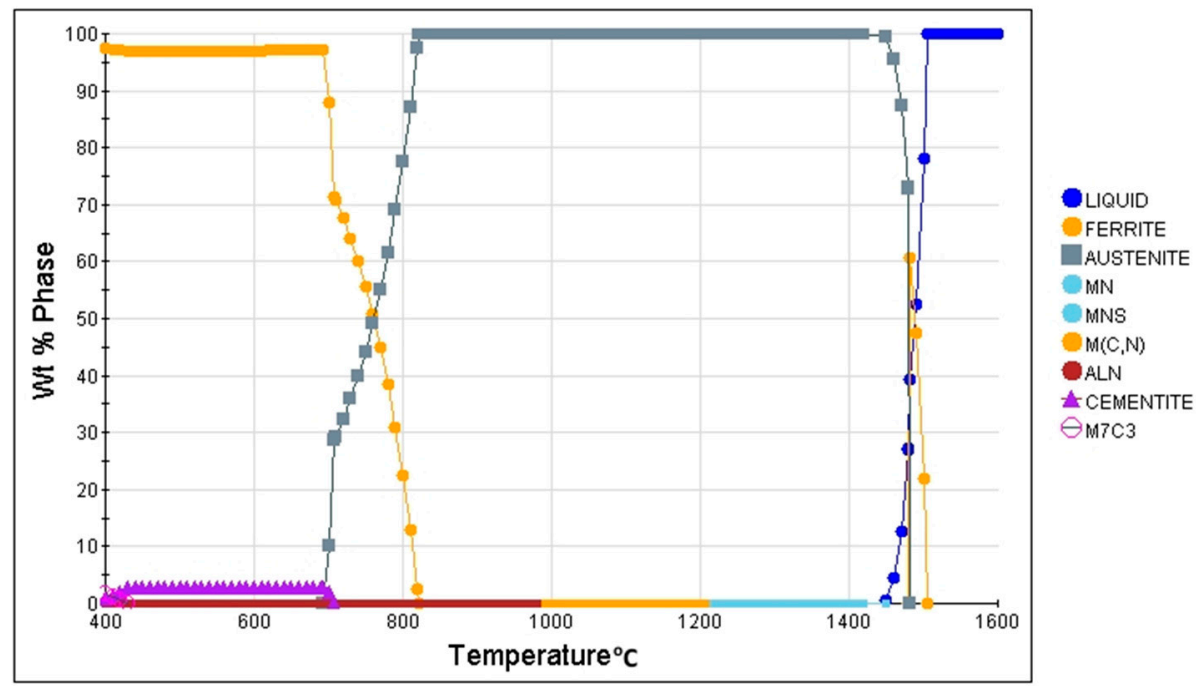

Figure 5. Thermodynamic evolution of the phases determined using JMatPro software.

Figure 6 shows the calculated continuous cooling transformation (CCT) diagram of the analyzed steel using the JMatPro software. The ferritic transformation starting temperature $\left(\mathrm{F}_{\mathrm{s}}\right)$ is equal to $822{ }^{\circ} \mathrm{C}$ for equilibrium conditions. It decreases with increasing cooling rate, which was kept constant for the whole temperature range. Based on the obtained graph, cooling rates faster than $10^{\circ} \mathrm{C} / \mathrm{s}$ are required to prevent a pearlitic transformation. The pearlite would consume carbon, which is needed for the stabilization of retained austenite in TRIP steels. The bainite is formed below $500{ }^{\circ} \mathrm{C}$, whereas the martensite start temperature $\left(\mathrm{M}_{\mathrm{s}}\right)$ is about $390^{\circ} \mathrm{C}$. 
CCT

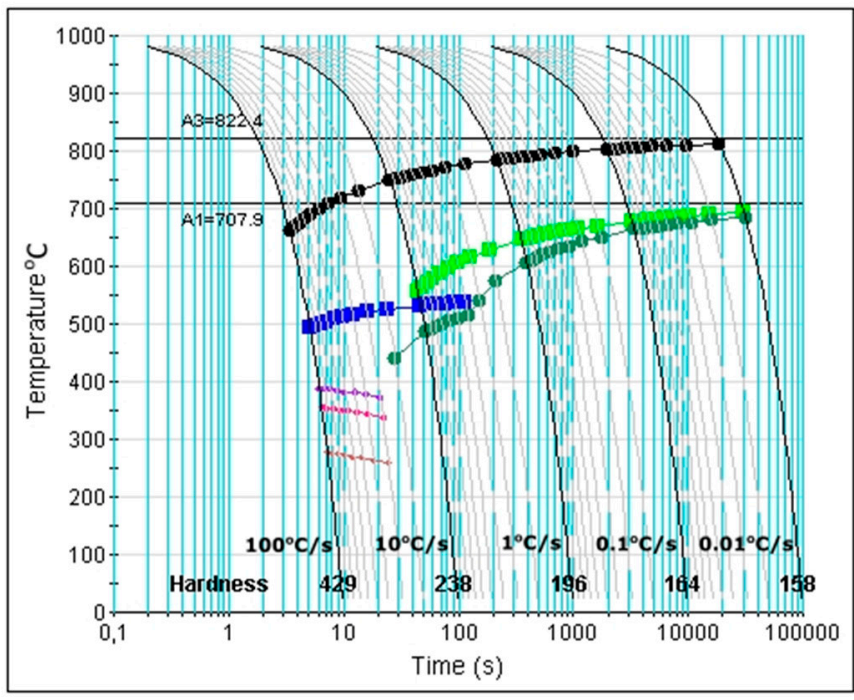

Austenitisation temperature (C) : 1000.0 Grain size : 9.0 ASTM
COMPOSITION (\%)

Fe: 97.8063

Al: 0.02

Mn: 1.41

$\mathrm{Nb}: 0.027$

Si: 0.5

Ti: 0.01

C: 0.2

N: 0.0047

P: 0.014

S: 0.008

TRANSITIONS: (C)

A3: 822.4

Pearlite: 707.9

Bainite: 581.5

Figure 6. A continuous cooling transformation (CCT) diagram of the analyzed steel.

The results of the calculation of the time-temperature-transformation (TTT) diagram are presented in Figure 7. It can be seen that the pearlite trasformation is delayed to longer times at temperatures above $650{ }^{\circ} \mathrm{C}$. There is a risk of pearlite precipitation after about $10 \mathrm{~s}$ at $600{ }^{\circ} \mathrm{C}$. The ferritic and bainitic transformations are left-shifted compared with the CCT diagram. The time needed for a complete bainitic transformaton under isothermal conditions is relatively short, i.e., ca. $20 \mathrm{~s}$. The generated diagrams indicate that there are conditions to design a cooling path consisting of ferrite and bainite, but it requires a multistep design instead of continuous cooling [11].

TTT

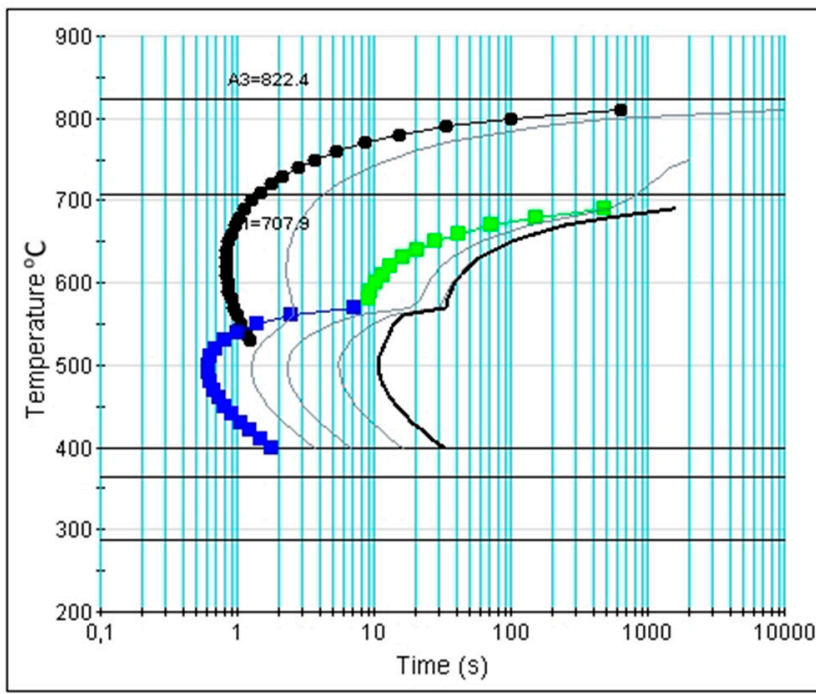

Austenitisation temperature (C) : 1000.0 Grain size : 9.0 ASTM
COMPOSITION $(\%)$

Fe: 97.8063

Al: 0.02

Mn: 1.41

$\mathrm{Nb}: 0.027$

Si: 0.5

Ti: 0.01

C: 0.2

N: 0.0047

P: 0.014

S: 0.008

TRANSITIONS: (C)

A3: 822.4

Pearlite: 707.9

Bainite: 581.5

Martensite:

Start: 398.0

50\%: 364.6

90\%: 286.9

Figure 7. A time-temperature-transformation (TTT) diagram of the analyzed steel. 


\subsection{CCT and DCCT Diagrams}

The calculated diagrams were experimentally verified in dilatometric tests. Two types of the diagrams were determined: the CCT diagram for undeformed specimens (Figure 8) and the DCCT (deformation continuous cooling transformation) diagram for deformed specimens (Figure 9). In general, argon cooling was applied. Helium was used for cooling rates faster than $60^{\circ} \mathrm{C} / \mathrm{s}$. Hence, the cooling rates covered the entire austenite decomposition range. They were kept stable during the experiment. These diagrams are very important tools for designing a multistep cooling schedule $[4,7]$.

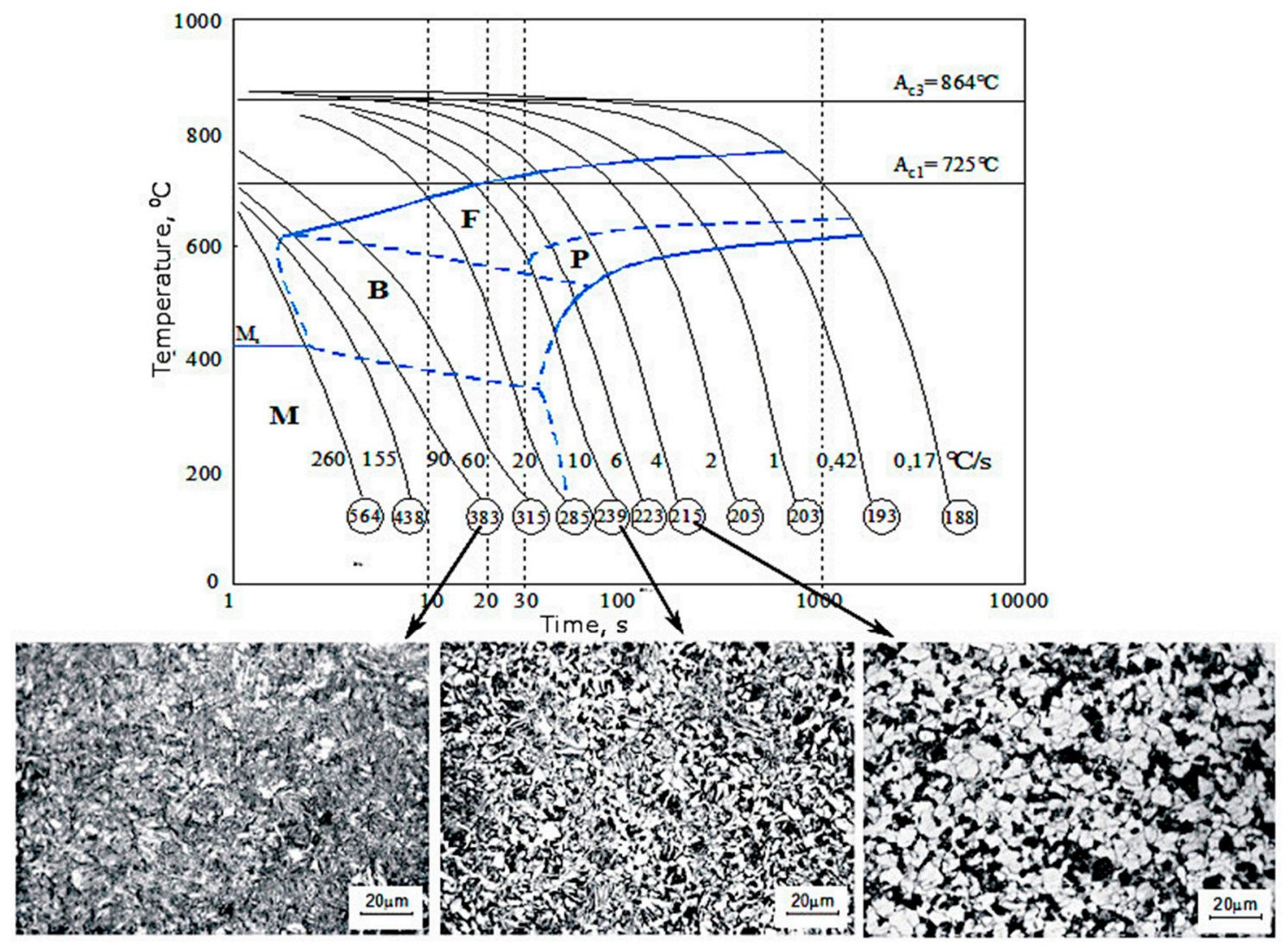

Figure 8. CCT diagram of supercooled austenite transformations of the analyzed steel, and microstructures obtained for different cooling rates from $875^{\circ} \mathrm{C}$.

The first important information obtained from these diagrams includes critical temperatures: $\mathrm{A}_{\mathrm{c} 1}$ is equal to $725{ }^{\circ} \mathrm{C}, \mathrm{A}_{\mathrm{c} 3}=864^{\circ} \mathrm{C}$, and $\mathrm{M}_{\mathrm{s}}=418{ }^{\circ} \mathrm{C}$. These temperatures slighty differ fom the calculated ones. It can be seen that the calculated cooling rate (using JMatPro) preventing a pearlite transformation coresponds well to that obtained on the real CCT diagram (about $10^{\circ} \mathrm{C} / \mathrm{s}$ ). The microstructure of undeformed steels changes from ferritic-pearlitic for cooling rates lower than $6{ }^{\circ} \mathrm{C} / \mathrm{s}$, through ferritic-bainitic in the range $10-60{ }^{\circ} \mathrm{C} / \mathrm{s}$ and bainitic-martensitic $\left(90-155^{\circ} \mathrm{C} / \mathrm{s}\right)$, to pure martensitic microstructures for cooling rates higher than $260^{\circ} \mathrm{C} / \mathrm{s}$. (Figure 8). The obtained microstructures of the steel are relatively fine-grained, presumably due to the precipitation of TiN and $\mathrm{Nb}(\mathrm{CN})$.

The DCCT diagram obtained for the specimens deformed at $875{ }^{\circ} \mathrm{C}$ put on the CCT diagram is shown in Figure 9. A distinct change of phase transformation kinetics is visible after plastic deformation. One can see that a major effect is the displacement of all phase transformations to higher temperatures and shorter times. The reason for these shifts is the increased diffusity of elements in the deformed austenite and a higher density of preferrable nucleation places for diffusional transformation products. Such places are especially shear bands and grain boundaries containing increased dislocation density [11-13]. The shift of ferritic and bainitic transformations creates better 
conditions for the realization of multistep cooling because these products can be produced for shorter times. It is especially important in industrial practice due to the short cooling sections available $[15,18]$.

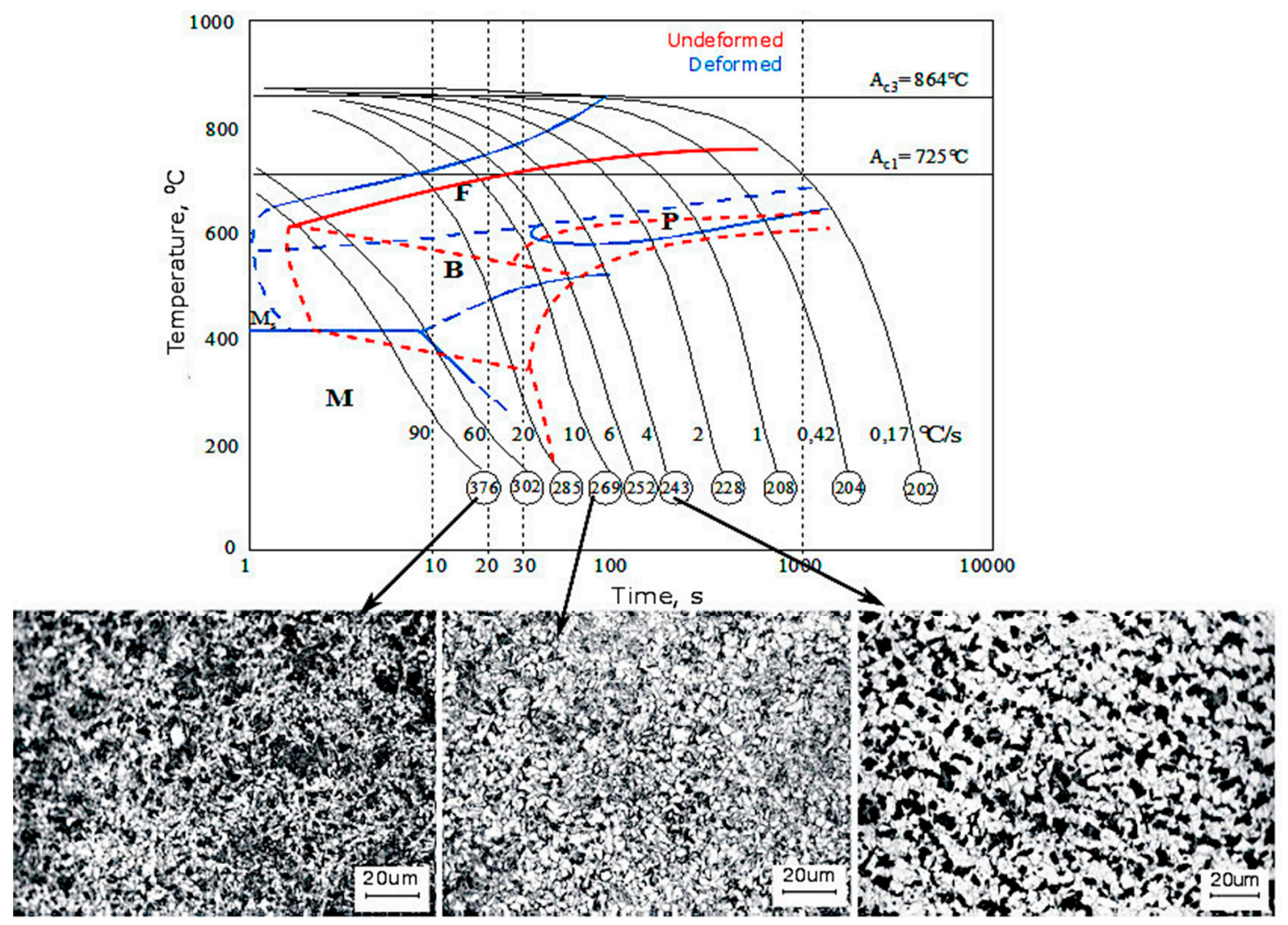

Figure 9. DCCT diagram of supercooled austenite transformations for deformed specimens superimposed on the CCT diagram, and microstructures obtained for different cooling rates from the deformation temperature of $875^{\circ} \mathrm{C}$.

The plastically deformed microstructures are more fine-grained when compared to the undeformed specimens. This is due to the higher number of nucleation places for ferrite and bainite. The size of grains is an important factor for the stability of retained austenite [6,10]. Its decrease favors the stability of the $\gamma$ phase. Jimenez-Melero et al. [28] reported that there is a minimum volume size of austenite grains, equal to $5 \mu \mathrm{m}^{3}$, below which the martensitic transformation of austenite does not occur.

The results indicate that the plastic deformation significantly affects the technological windows required for producing multiphase microstructures consisting of ferrite, bainite, and retained austenite. The major positive effects are shifting the ferrite and bainite regions to shorter times and higher temperatures. In practice, this means the faster production of a sufficient amount of ferrite (ca. 60\%-70\%) in typical TRIP steels $[4,10]$. This is especially important for short run-out tables in technological hot rolling lines [22,25]. The detailed microstructures and mechanical properties for such a designed thermomechanical approach can be found elsewhere [11].

\section{Conclusions}

The work addressed the thermodynamic calculations of precipitation processes and austenite decomposition in a low-Si Nb-Ti-microalloyed automotive steel. The thermodynamic calculations of precipitation processes indicated that TiN particles should limit the grain growth during the austenitizing step at $1100{ }^{\circ} \mathrm{C}$, whereas $\mathrm{Nb}(\mathrm{C}, \mathrm{N})$ particles should be effectively precipitated during hot deformation in the austenite range. The effects of alloying (Mn and $\mathrm{Si}$ ) and plastic deformation 
on the austenite decomposition were identified. The DCCT diagram possessed a large ferrite region beneficial for the production of ferrite within a reasonable time after finishing rolling. The technological windows for the realization of ferrite and bainite transformations from the deformed austenite were identified. The plastically deformed samples showed more fine-grained microstructures compared to nondeformed samples. This should favor the stabilization of some fraction of retained austenite through grain refinement stabilization during incomplete bainitic transformation.

Author Contributions: A.G. conceived, designed, and performed the experiments and reviewed the paper; M.M. performed the thermodynamic calculations and wrote the paper; W.Z. performed dilatometric experiments, calculated CCT and TTT diagrams, analysed the data, and reviewed the paper.

Funding: The work was financially supported by statutory funds from the Faculty of Mechanical Engineering of Silesian University of Technology in 2018.

Conflicts of Interest: The authors declare no conflict of interest.

\section{References}

1. Baker, T.N. Microalloyed steels. Ironmak. Steelmak. 2016, 43, 264-307. [CrossRef]

2. Muszka, K.; Dymek, S.; Majta, J.; Hodgson, P. Microstructure and properties of a C-Mn steel subjected to heavy plastic deformation. Arch. Metall. Mater. 2010, 55, 641-645.

3. Smith, D.; Joris, O.P.J.; Sankaran, A.; Weekes, H.E.; Bull, D.J.; Prior, T.J.; Dye, D.; Errandonea, D.; Proctor, J.E. On the high-pressure phase stability and elastic properties of $\beta$-titanium alloys. J. Phys. Condens. Matter 2017, 29, 155401. [CrossRef] [PubMed]

4. Zhang, M.; Li, L.; Fu, R.Y.; Krizan, D.; De Cooman, B.C. Continuous cooling transformation diagrams and properties of micro-alloyed TRIP steels. Mater. Sci. Eng. A 2006, 438-440, 296-299. [CrossRef]

5. Grajcar, A.; Różański, M.; Kamińska, M.; Grzegorczyk, B. Effect of gas atmosphere on the non-metallic inclusions in laser-welded TRIP steel with Al and Si additions. Mater. Technol. 2016, 50, 945-950. [CrossRef]

6. Pereloma, E.V.; Al-Harbi, F.; Gazder, A.A. The crystallography of carbide-free bainites in thermo-mechanically processed low Si transformation-induced plasticity steels. J. Alloys Compd. 2014, 615, 96-110. [CrossRef]

7. Kaijalainen, A.; Vahakuopus, N.; Somani, M.; Mehtonen, S.; Porter, D.; Komi, J. The effects of finish rolling temperature and niobium microalloying on the microstructure and properties of a direct quenched high-strength steel. Arch. Metall. Mater. 2017, 62, 619-626. [CrossRef]

8. Grajcar, A.; Radwański, K. Microstructural comparison of the thermomechanically treated and cold deformed Nb-microalloyed TRIP steel. Mater. Technol. 2014, 48, 679-683.

9. Caballero, F.B.; Roelofs, H.; Hasler, S.; Capadevila, C.; Chao, J.; Cornide, J.; Garcia-Mateo, C. Influence of bainite morphology on impact toughness of continuously cooled cementite free bainitic steels. Mater. Sci. Technol. 2012, 28, 95-102. [CrossRef]

10. Ranjan, R.; Beladi, H.; Singh, S.B.; Hodgson, P.D. Thermo-mechanical processing of TRIP-aided steels. Metall. Mater. Trans. A 2015, 46, 3232-3247. [CrossRef]

11. Adamczyk, J.; Grajcar, A. Structure and mechanical properties of DP-type and TRIP-type sheets obtained after the thermomechanical processing. J. Mater. Process. Technol. 2005, 162-163, 267-274. [CrossRef]

12. Tsukatani, I.; Hashimoto, S.; Inoue, T. Effects of silicon and manganese addition on mechanical properties of high-strength hot-rolled sheet steel containing retained austenite. ISIJ Int. 1991, 31, 992-1000. [CrossRef]

13. Kawulok, R.; Schindler, I.; Kawulok, P.; Rusz, S.; Opela, P.; Kliber, J.; Solowski, Z.; Cmiel, K.M.; Podolinsky, P.; Malis, M.; et al. Transformation kinetics of selected steel grades after plastic deformation. Metalurgija 2016, 55, 357-360.

14. Grajcar, A. Thermodynamic analysis of precipitation processes in Nb-Ti-microalloyed Si-Al TRIP steel. J. Therm. Anal. Calorim. 2014, 118, 1011-1020. [CrossRef]

15. De Ardo, A.J.; Garcia, J.E.; Hua, M.; Garcia, C.I. A new frontier in microalloying: Advanced high strength, coated sheet steels. Mater. Sci. Forum 2005, 500-501, 27-38. [CrossRef]

16. Nasr El-Din, H. Effect of cold deformation and multiphase treatment conditions on the characterization of low-carbon, low-silicon multiphase steel. Steel Grips 2005, 3, 196-205.

17. Radwanski, A. Structural characterization of low-carbon multiphase steels merging advanced research methods with light optical microscopy. Arch. Civ. Mech. Eng. 2016, 16, 282-293. [CrossRef] 
18. Opiela, M. Thermodynamic analysis of the precipitation of carbonitrides in microalloyed steels. Mater. Technol. 2015, 49, 395-401. [CrossRef]

19. Kurc-Lisiecka, A.; Lisiecki, A. Laser welding of the new grade of advanced high-strength steel Domex 960. Mater. Technol. 2017, 51, 199-204.

20. Opiela, M.; Grajcar, A. Hot deformation behavior and softening kinetics of Ti-V-B microalloyed steels. Arch. Civ. Mech. Eng. 2012, 12, 327-333. [CrossRef]

21. Kucerova, L.; Opatova, K.; Kana, J.; Jirkova, H. High versatility of niobium alloyed AHSS. Arch. Metall. Mater. 2017, 62, 1485-1491. [CrossRef]

22. Uranga, P.; Lopez, B.; Rodriguez-Ibabe, J.M. Microstructural modelling of $\mathrm{Nb}$ microalloyed steels during thin slab direct rolling processing. Steel Res. Int. 2007, 78, 199-209. [CrossRef]

23. Krizan, D.; Spiradek-Hahn, K.; Pichler, A. Relationship between microstructure and mechanical properties in Nb-V microalloyed TRIP steel. Mater. Sci. Technol. 2015, 31, 661-668. [CrossRef]

24. Gladman, T. The Physical Metallurgy of Microalloyed Steels; The Institute of Materials, University Press: Cambridge, UK, 1997.

25. Jung, J.; Lee, S.J.; Kim, S.; De Cooman, B.C. Effect of Ti additions on micro-alloyed Nb TRIP steel. Steel Res. Int. 2011, 82, 857-865. [CrossRef]

26. Irvine, K.J.; Pickering, F.B.; Gladman, T. Grain refined C-Mn steels. J. Iron Steel Inst. 1967, 205, $161-182$.

27. Gorka, J. Microstructure and properties of the high-temperature HAZ of thermo-mechanically treated S700MC high-yield-strength steel. Mater. Technol. 2016, 50, 617-621. [CrossRef]

28. Jimenez-Melero, E.; van Dijk, N.H.; Zhao, L.; Sietsma, J.; Offerman, S.E.; Wright, J.P.; van der Zwaag, S. Martensitic transformation of individual grains in low-alloyed TRIP steels. Scr. Mater. 2007, 56, 421-424. [CrossRef]

29. Siciliano, F.; Jonas, J.J. Mathematical modeling of the hot strip rolling of microalloyed Nb, multiply-alloyed Cr-Mo, and plain C-Mn steels. Metall. Mater. Trans. A 2000, 31A, 511-530. [CrossRef]

30. Siciliano, F.; Poliak, E.I. Modeling of the resistance to hot deformation and the effects of microalloying in high-Al steels under industrial conditions. Mater. Sci. Forum 2005, 500-501, 195-202. [CrossRef]

31. Nowotnik, A.; Siwecki, T. The effect of TMCP parameters on the microstructure and mechanical properties of Ti-Nb microalloyed steel. J. Microsc. 2010, 237, 258-262. [CrossRef]

32. Saunders, N.; Guo, Z.; Li, X.; Miodownik, A.P.; Schille, J.P. Using JMatPro to model materials properties and behavior. JOM 2003, 55, 60-65. [CrossRef] 